\title{
Development of a Fast-Response Diamond Calorimeter Heat Transfer Gauge
}

\author{
Rowland T. Penty Geraets * and Matthew McGilvray ${ }^{\dagger}$ and Luke J. Doherty \\ University of Oxford, Oxford, U.K. \\ Richard G. Morgan ${ }^{\S}$ and Christopher M. James ${ }^{\text {It }}$ \\ University of Queensland, Brisbane, Australia \\ David R. Buttsworth" \\ University of Southern Queensland, Toowoomba, Australia
}

\begin{abstract}
A robust fast-response calorimeter heat transfer gauge called the Diamond Heat Transfer Gauge has been developed for use in transient hypersonic ground test facilities. Gauges have been produced using discs of synthetic diamond $150 \mu \mathrm{m}$ to $325 \mu \mathrm{m}$ thick as a calorimeter and platinum thin-film resistance temperature detectors to measure temperature rise. The response times of the gauges are dependent on calorimeter thickness and range between $10.6 \mu \mathrm{s}$ to $49.6 \mu \mathrm{s}$. Heat fluxes greater than $100 \mathrm{MWm}^{-2}$ have been measured at the stagnation point of a model in flows with total enthalpies of up to $70 \mathrm{MJkg}^{-1}$ over multiple shots an expansion tunnel. Experimentally measured heat fluxes compare well with measurements from surface abraded coaxial thermocouples gauges and an empirical correlation.
\end{abstract}

\section{Nomenclature}

$a \quad=\quad$ ratio of thermal products

$\alpha=$ thermal diffusivity, $\mathrm{m}^{2} \mathrm{~s}^{-1}$

$\alpha_{R}=$ coefficient of temperature with resistance, $\mathrm{K}^{-1}$

$e \quad=\quad$ thermal effusivity, $\mathrm{W} \mathrm{m}^{-1} \mathrm{~K}^{-1} \mathrm{~s}^{-0.5}$

$q=$ heat flux, $\mathrm{W} \mathrm{m}^{-2}$

$c_{p}=$ specific heat capacity at constant pressure, $\mathrm{J} \mathrm{kg}^{-} 1 \mathrm{~K}^{-1}$

$H \quad=\quad$ enthalpy, $\mathrm{J} \mathrm{kg}^{-1}$

$k=$ thermal conductivity

$l=$ calorimeter thickness, $\mathrm{m}$

\footnotetext{
*DPhil Candidate, Department of Engineering Science, The University of Oxford.

${ }^{\dagger}$ Associate Professor, Department of Engineering Science, The University of Oxford.

${ }^{\ddagger}$ Senior Research Associate, Department of Engineering Science, The University of Oxford

${ }^{\S}$ Professor, Centre for Hypersonics, The University of Queensland.

IIResearch Scholar, Centre for Hypersonics, The University of Queensland

"Professor, School of Mechanical and Electrical Engineering, The University of Southern Queensland
} 


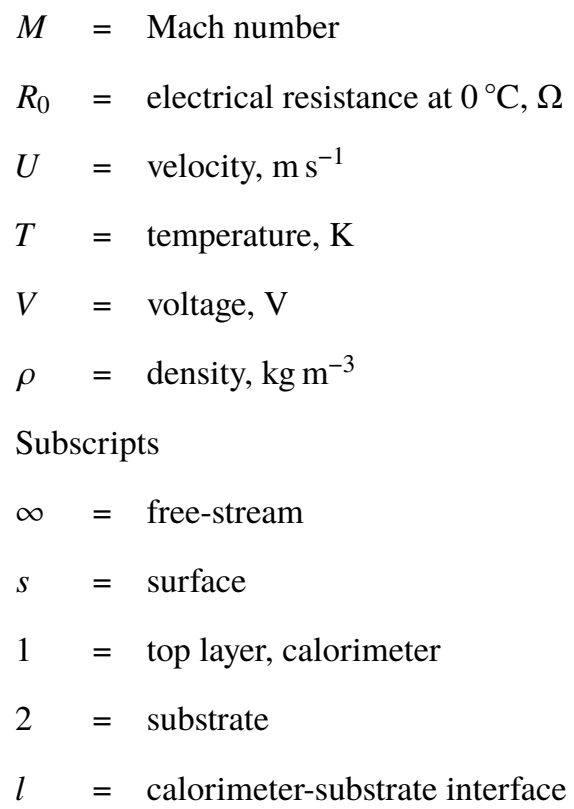

\section{Introduction}

High enthalpy ground test facilities produce challenging environments in which to make surface heat flux measurements. Ultra-high speed pulse flow wind tunnels capable of producing total enthalpies equivalent to flight and matching binary scaling parameters have test times of the order $10 \mu$ s to $2 \mathrm{~ms}[1]$. Instrumentation used must have sufficiently fast response times to produce useful data while also surviving both the extreme heat rates and impacts from fragments of metallic and plastic diaphragms that impact models at high speeds.

Global heat transfer measurement techniques have improved recently. Fast-response Temperature Sensitive Paints (TSP) have been developed but has drawbacks including: limited durability in high enthalpy facilities (perhaps only lasting one tunnel shot)[2], the need for good optical access which limits model complexity, the need for in-situ calibrations, and degradation of the luminophore over a time-scale of hours[3]. Infra-Red Thermography is currently limited low resolution scans at frame-rate required for time-resolved measurements in high enthalpy wind tunnels[4]. Both methods can also suffer from measurement complications due to non-transparent and radiating flows.

Thin-film heat transfer gauges which are commonly used in low enthalpy testing only survive one shot when mounted on blunt body geometry in high enthalpy facilities [5, 6]. Surface junction thermocouples [7-[10] are very robust but often require re-abrading or re-machining between shots due to damage from the flow. Additionally, the assumption of heat conduction into a homogeneous medium most often used to calculate heat flux from a temperature measurement[11] is not valid on a tens of micro-second time-scale[9, 12]. At longer time-scales reports of thermal product values for similar gauges vary by as much as $15 \%$ [13, 14], and can vary by as much as $20 \%$ depending on the method used to form the junction[12]. Good electrical grounding is required to avoid interference from ionised flows due to exposed 
Table 1 Details of current types of DHTG. Estimated response times are calculated using Eq. 5 .

\begin{tabular}{llll}
\hline $\begin{array}{l}\text { DHTG } \\
\text { Type }\end{array}$ & $\begin{array}{l}\text { Diamond } \\
\text { thickness, } \mu \mathrm{m}\end{array}$ & $\begin{array}{l}\text { Diamond } \\
\text { Type }\end{array}$ & DHTG Numbers \\
\hline 1 & 150 & Transparent PCD (TPCD) & 1 to $5,16,17$ \\
2 & 220 & Opaque PCD (OPCD) & 6 to 10,19 \\
3 & 325 & Transparent PCD (TPCD) & 11 to $15,18,20$ \\
\hline
\end{tabular}

metallic junctions, which is difficult to achieve in practice.

This paper describes the development and testing of the Diamond Heat Transfer Gauge, a new thin-film calorimeter gauge, designed for use in high enthalpy short-duration wind tunnels. The short response-time required is achieved using a calorimeter made from synthetic CVD (Chemical Vapour Depisition) diamond which has an extremely high thermal diffusivity, mainly due to its exceptionally high thermal conductivity of $1000 \mathrm{Wm}^{-1} \mathrm{~K}^{-1}$ to $2600 \mathrm{Wm}^{-1} \mathrm{~K}^{-1}$ [15, 16]. A platinum thin-film RTD is used to measure the temperature of the calorimeter accurately and quickly.

The only known study in the literature where CVD diamond is a component of a heat transfer gauge was published by Follador[17], however the focus of the paper is on the growth of a diamond layer onto a thin-film gauge substrate and no experimental heat flux or temperature measurements are reported. Initial investigation of the present gauge using CVD diamond as the calorimeter[18] was undertaken at The University of Oxford by Clark[19] and Vanyai[20]. The present paper details the investigation of the concept, the development of the heat transfer gauge, and an experimental campaign in the X2 expansion tunnel at the University of Queensland where measured heat flux and robustness were compared to abraded surface-junction thermocouples[7].

\section{The Diamond Heat Transfer Gauge}

A cross-sectional schematic and photograph of the gauge are shown in Fig. 1. The calorimeter element of the DHTG consists of a disk of CVD diamond with a platinum thin-film Resistance Temperature Detector (RTD) sputtered on the rear surface. The diamond piece has a diameter of $2.52 \mathrm{~mm}$ and a thickness of $150 \mu \mathrm{m}, 220 \mu \mathrm{m}$, or $325 \mu \mathrm{m}$, and is bonded into a steel housing using a low thermal conductivity adhesive with a high working temperature. The range of gauges detailed in Table 1 were made with different diamond thicknesses and diamond types to study the effect of calorimeter thickness on response time, accuracy, and durability. Gauges with $75 \mu \mathrm{m}$ thick single crystal diamond calorimeters have been manufactured but were not used in this study.

\section{A. Calculation of Surface Heat Flux}

For a thin-skin calorimeter, surface heat flux can be calculated by measuring the transient temperature of the calorimeter, and subsequent analysis of the heat balance. Figure 2 shows a schematic of a two-layer semi-infinite system for which the equation for the diffusion of heat can be written as Eq. (1), where $n=1$ is the calorimeter layer and $n=2$ 


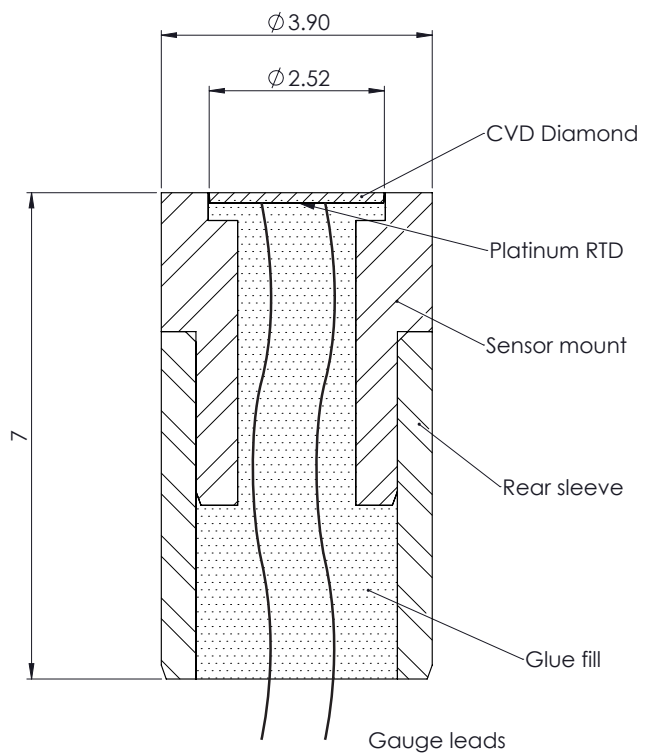

(a)

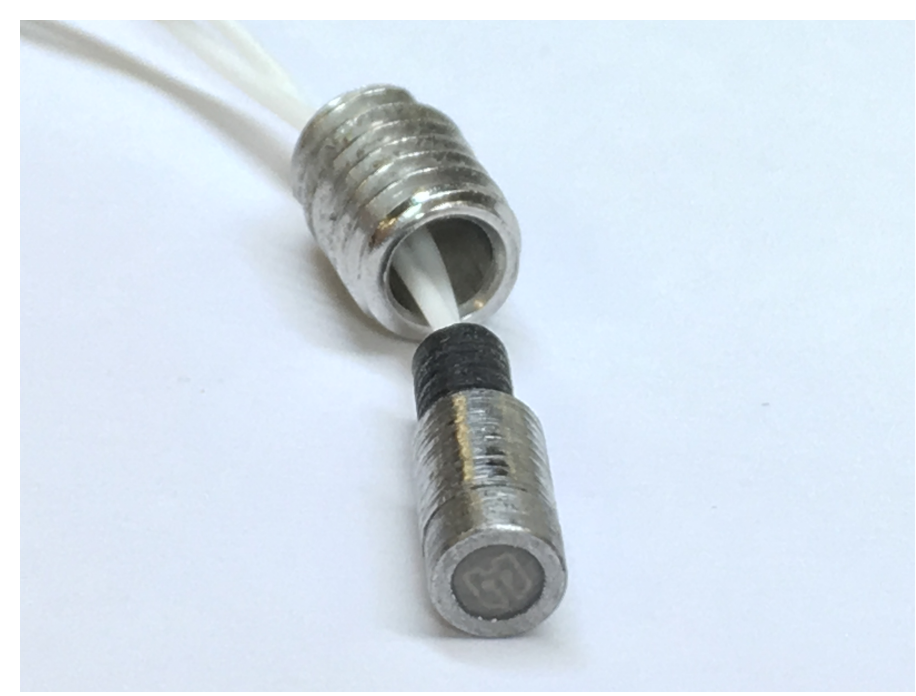

(b)

Fig. 1 A schematic (a) and photo (b) of DHTG20. The serpentine platinum RTD track is visible through the transparent PCD diamond in (b).

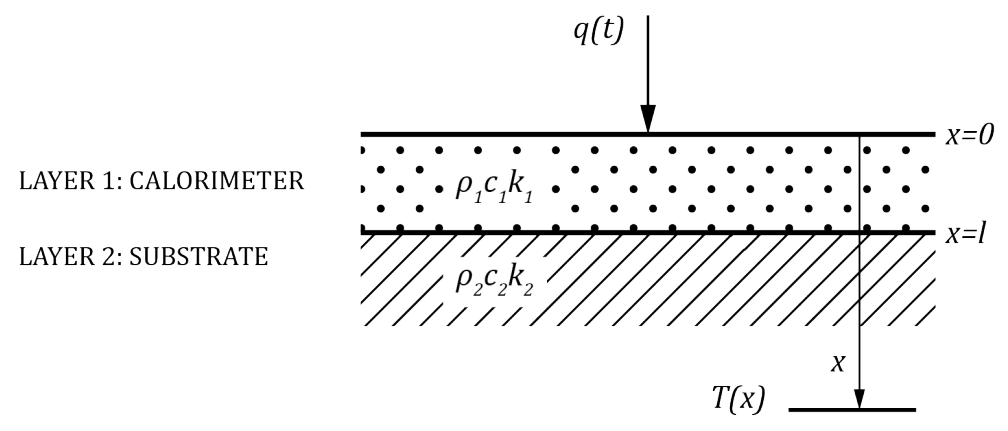

Fig. 2 Schematic of a one-dimensional analysis of a calorimeter gauge.

is the substrate.

$$
\frac{\partial T_{n}}{\partial t}=\alpha_{n} \frac{\partial T_{n}}{\partial x^{2}}
$$

The surface heat flux can be written using the calorimeter equation with temperature dependent thermal properties:

$$
q_{s}(t)=\int_{0}^{l} \rho_{1}(T) c_{p, 1}(T) \frac{d T(t)}{d t} d x+q_{l o s s}(t)
$$

Defining the mean temperature as $\bar{T}$, Eq. (2) can be written:

$$
q_{s}(t)=\rho_{1}(\bar{T}) c_{p, 1}(\bar{T}) l \frac{d \bar{T}(t)}{d t}+q_{l o s s}(t)
$$


Assuming radiative losses are negligible, the only loss from layer 1, the calorimeter, in the system shown in Fig. 2 is conduction into the substrate.

If the temperature at $x=l$ is known or measured $\left(T_{l}\right)$, the loss can be calculated assuming one-dimensional conduction into a semi-infinite medium[11]:

$$
q_{\text {loss }}(t)=\sqrt{\frac{\rho_{2} c_{p, 2} k_{2}}{\pi}}\left[\frac{T_{l}(t)}{\sqrt{t}}+\int_{0}^{t} \frac{T_{l}(t)-T_{l}(\tau)}{(t-\tau)^{3 / 2}} d \tau\right]
$$

Equation 3 requires knowledge of the mean temperature of the calorimeter and the derivative of the mean temperature, with respect to time, to reproduce the surface heat flux. It is necessary to make the two assumptions relating the measured temperature to the mean temperature: firstly that $d T_{l}=d \bar{T}$ and secondly that $d T_{l} / d t=d \bar{T} / d t$. Section III presents a model of the DHTG where these assumptions are investigated.

\section{B. Material Properties and Response Time}

Material properties at room temperature of two grades of synthetic diamond are compared to Silicon Carbide (SiC) and copper (two alternative calorimeter materials) in Table 2. The variation with temperature of thermal conductivity and specific heat capacity for CVD diamond are shown in Fig. 3. The specific heat capacity is assumed to be the same for both grades of diamond[21]. The density of diamond has insignificant temperature dependence over the range of interest.

Schultz and Jones [11] give Eq. [5] as approximation for the response time of a calorimeter defined as the time taken for the rear surface temperature gradient to reach $99 \%$ of the steady state value in response to a step change in heat flux at the front surface. Response time can be decreased by using a thinner calorimeter with a higher thermal diffusivity. The approximate response time of a calorimeter gauge using the materials in Table 2 is plotted in Fig. 4 as a function of thickness. For a given thickness of calorimeter, using transparent PCD instead of copper can give an order of magnitude reduction in response time. The approximate response times of the DHTG types detailed in Table 1 are $10.6 \mu$ s for Type $1,33.0 \mu$ s for Type 2 , and $49.6 \mu$ s for Type 3 .

$$
\tau_{r}=\frac{l^{2}}{2 \alpha_{1}}
$$

\section{RTD Calibration}

During an experiment, as the temperature of the platinum film changes, so does its electrical resistance. The film is supplied with a constant current of approximately $10 \mathrm{~mA}$, and change in resistance can be detected as a change in voltage. The experimental temperature change is calculated using Eq. (6), where $V_{r e f}$ is the voltage measured with the gauge at isothermal conditions at a temperature $T_{r e f}$ prior to an experiment. The coefficient of resistance with 
Table 2 Thermal properties of possible calorimeter materials at $20^{\circ} \mathrm{C}[15,22,23]$.

\begin{tabular}{llllll}
\hline Material Property & Units & $\begin{array}{l}\text { Transparent PCD } \\
\text { (TPCD) }\end{array}$ & $\begin{array}{l}\text { Opaque PCD } \\
\text { (OPCD) }\end{array}$ & SiC & Copper \\
\hline Density, $\rho$ & $\mathrm{kgm}^{-3}$ & 3514 & 3514 & 3100 & 8960 \\
Specific Heat Capacity, $c_{p}$ & $\mathrm{Jkg}^{-1} \mathrm{~K}^{-1}$ & 495 & 495 & 750 & 385 \\
Thermal Conductivity, $k$ & $\mathrm{Wm}^{-1} \mathrm{~K}^{-1}$ & 1852 & 1274 & 120 & 380 \\
Thermal Diffusivity, $\alpha$ & $10^{-6} \mathrm{~m}^{2} \mathrm{~s}^{-1}$ & 1064 & 732 & 52 & 114 \\
\hline
\end{tabular}

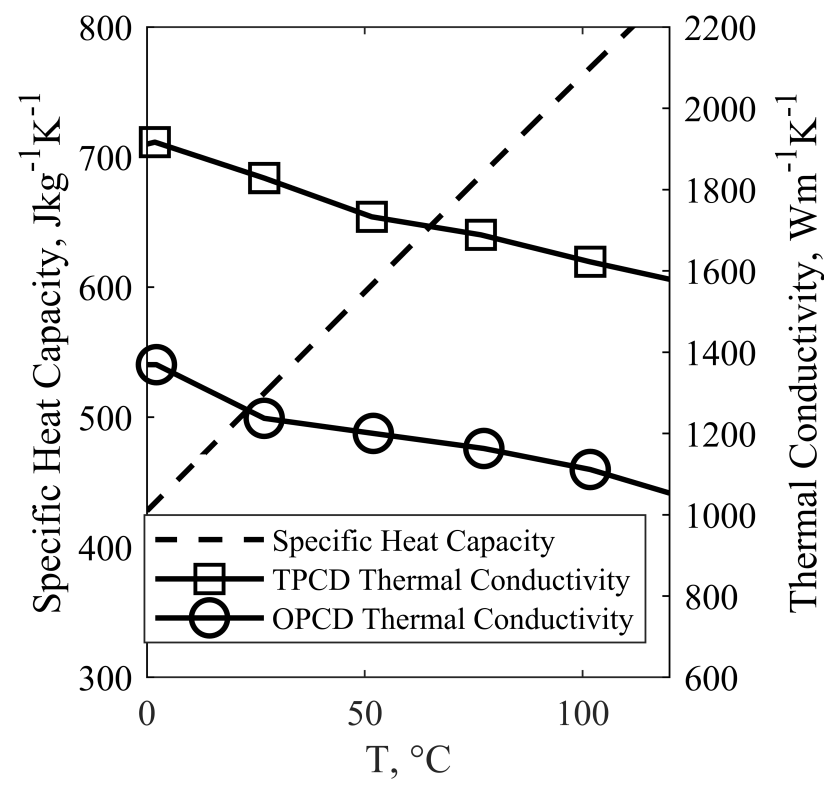

Fig. 3 Variation of thermal conductivity and specific heat capacity with temperature for transparent PCD diamond [15, 22]. 


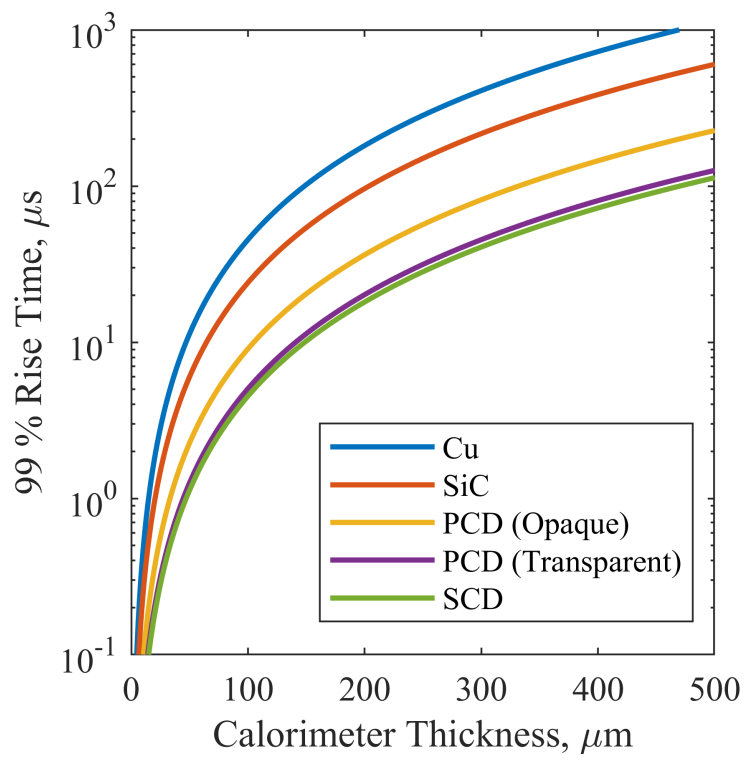

Fig. 4 The approximate rise time of an ideal calorimeter at room temperature as a function of thickness, Eq. 5 . Plotted for materials shown in Table 2.

temperature $\left(\alpha_{R}\right)$ for the RTD in each DHTG was found using the calibration process described by Collins[24].

$$
T(t)=\frac{V(t)-V_{r e f}}{\alpha_{R} V_{r e f}}+T_{r e f}
$$

\section{Finite Element Heat Conduction Model}

Although Schultz and Jones provide analytical equations for temperature at any depth in the simplified system shown in Fig. 2. the specific heat capacity and thermal conductivity of diamond are temperature dependent, as shown in the previous section. To assess the accuracy of the surface heat flux calculation with the assumptions presented in the previous section, a two-dimensional axisymmetric Finite Element model of a DHTG was used to model transient heat conduction in Comsol Multiphysics ${ }^{\circledR}$ [25].

Only the front $0.75 \mathrm{~mm}$ of Type 1 DHTG was modelled, as shown in Fig. 5. The $0.6 \mathrm{~mm}$ depth of adhesive is greater than the thermal penetration depth after $2000 \mu$ s. The mesh consisted of 15,500 triangular elements clustered towards the top surface and material boundaries. The two electrical gold leads of $60 \mu \mathrm{m}$ diameter were modelled as a single lead of $84.85 \mu \mathrm{m}$, preserving cross-sectional area. The thermophysical properties for the diamond were taken from Ref.[15]; those for steel were taken to be $\rho=7850 \mathrm{kgm}^{-3}, c_{p}=475 \mathrm{Jkg}^{-1} \mathrm{~K}^{-1}, k=44.5 \mathrm{Wm}^{-1} \mathrm{~K}^{-1}$; those for the epoxy were taken to be $\rho=1500 \mathrm{kgm}^{-3}, c_{p}=1000 \mathrm{Jkg}^{-1} \mathrm{~K}^{-1}, k=0.55 \mathrm{Wm}^{-1} \mathrm{~K}^{-1}$; and those for gold were taken to be $\rho=19300 \mathrm{kgm}^{-3}, c_{p}=129 \mathrm{Jkg}^{-1} \mathrm{~K}^{-1}, k=314 \mathrm{Wm}^{-1} \mathrm{~K}^{-1}$.

A constant heat flux of $q_{\text {applied }}=10 \mathrm{MW} / \mathrm{m}^{2}$ was used as the boundary condition across the top surface of the 


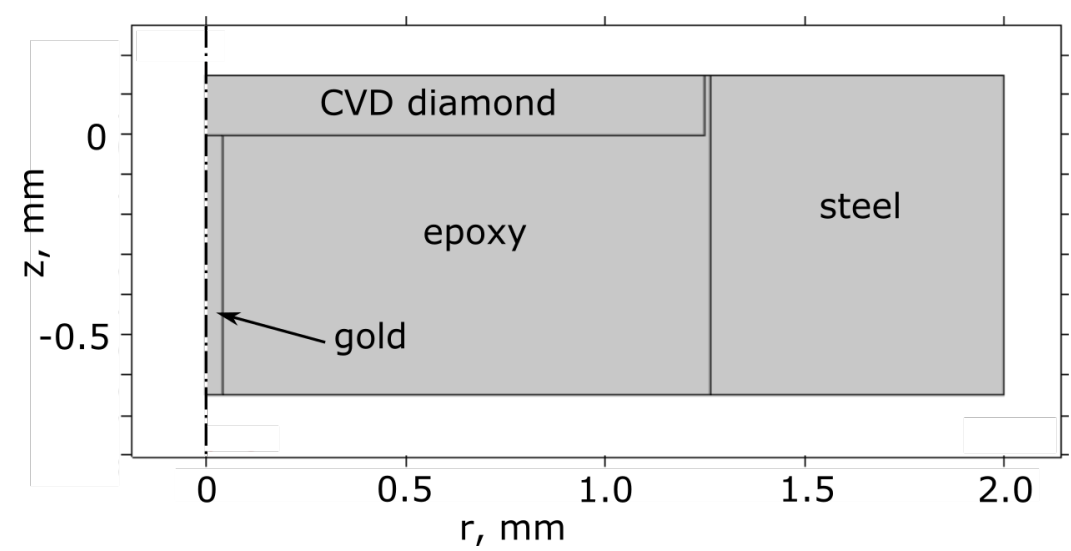

Fig. 5 The domain for the Finite Element model with material regions labelled.

domain. Adiabatic boundary conditions were used on all other external boundaries. The surface integral of temperature across the front $\left(T_{\text {front }}\right)$ and rear $\left(T_{\text {rear }}\right)$ side of the diamond were recorded, and are plotted in Fig. 6. The rear surface temperature output resembles that which the thin-film RTD would measure in the physical gauge. The difference in temperature across the diamond layer does not exceed $0.6 \mathrm{~K}$ in the simulation, therefore the assumption that $d T_{l}=d \bar{T}$ is valid, and spatial differences in material properties can be ignored when calculating surface heat flux.

The surface heat flux was calculated from $T_{\text {rear }}$ using Eq. (3). The result is shown in Fig. 7a, normalised by the actual input to the model. Figure $7 \mathrm{~b}$ shows the measurement error of the calculated heat flux. In both plots three lines are shown: the first (blue line) is calculated using Eq. (4) to correct for conductive losses from the diamond to the substrate, and with temperature dependent diamond properties; the second (orange line) is calculated in the same way but with constant diamond properties at the starting temperature; the third (yellow line) is calculated assuming no conductive losses from the calorimeter but temperature dependent diamond properties. By assuming that there are only losses through axial conduction, the heat flux calculated is accurate to within $3 \%$ after the initial rise time. Losses through radial conduction into the glue and steel, and axial conduction through the gold electrical wires account for the remaining error. If the change in specific heat capacity with temperature is neglected, the error in measured heat flux is significant. The estimated response time of $14.8 \mu$ s from this study is higher than the $10.9 \mu$ s estimated by Eq. (5) due to conduction out of the diamond into the adhesive.

\section{Experimental Set-up}

\section{A. Facility and Conditions}

The X2 Expansion Tube facility is a free-piston driven pulse flow wind tunnel which can produce scaled test flow conditions representative of atmospheric entry into most planets in our solar system[26]. X2 has multiple modes of operation, but for the purposes of this test campaign, it was operated as an expansion tunnel with a single driver tube and a diverging nozzle at the test section entrance. Details of X2 can be found in Gildfind et al.[27]. 


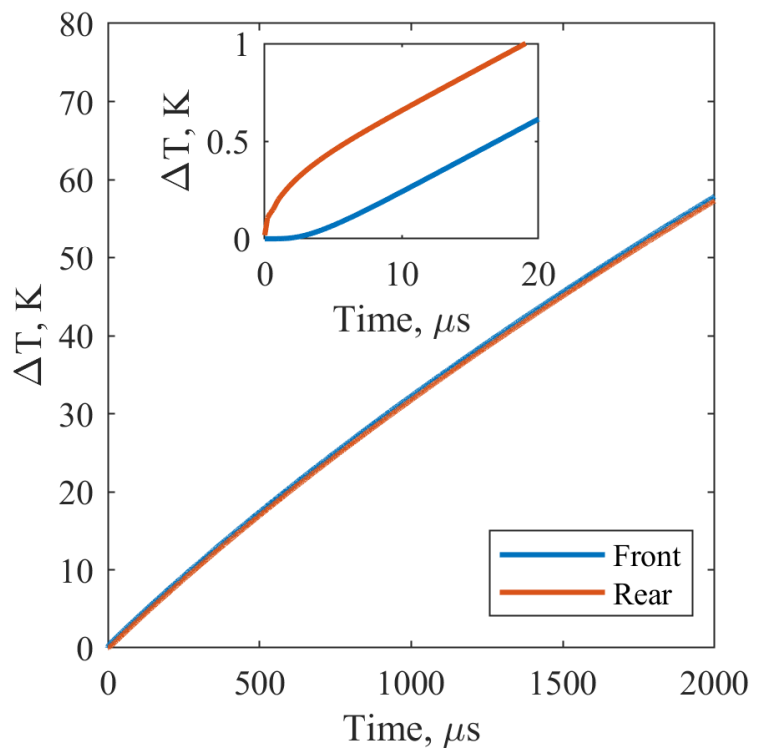

Fig. 6 Spatially averaged temperature rise across the front and rear surface of the diamond layer in the Finite Element model in response to a $10 \mathrm{MW} / \mathrm{m}^{2}$ heat flux applied at the surface.

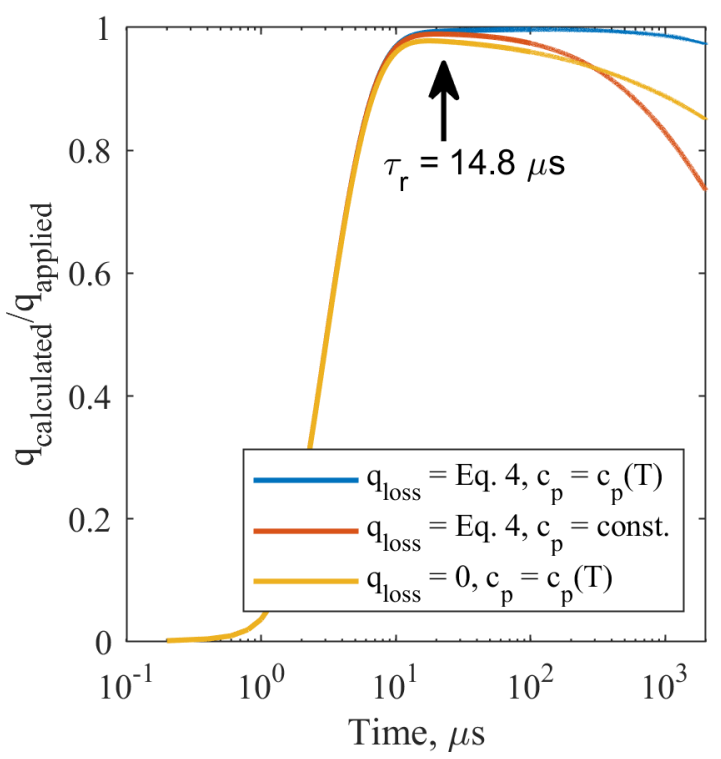

(a) Calcualted heat flux normalised by applied heat flux.

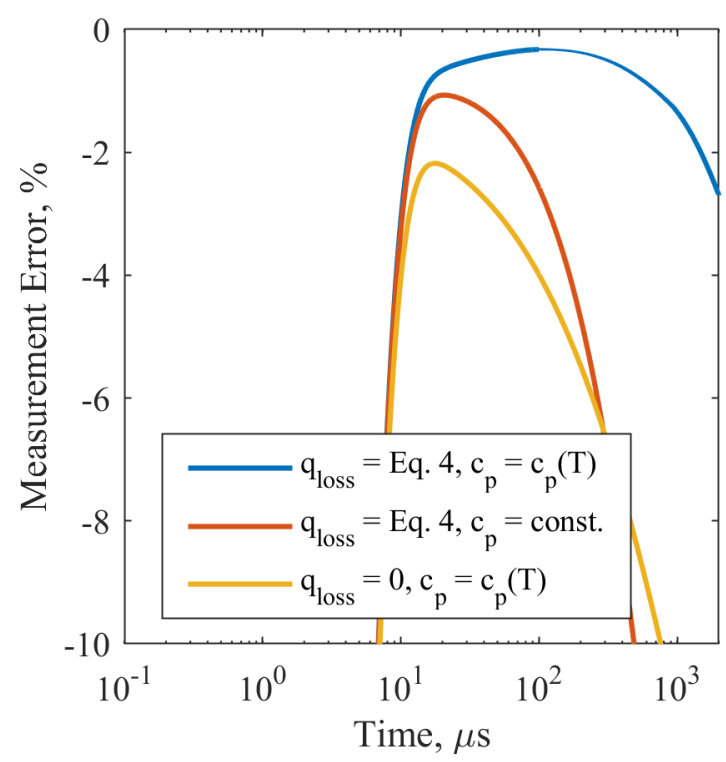

(b) Measurement error of calculated heat flux.

Fig. 7 Surface heat flux calculated using Eq. (3) from the temperature signal shown in Fig. 6 compared to the applied surface heat flux. 
Table 3 Details of the conditions used in the X2 experimental campaign. All conditions used air as the test gas.

\begin{tabular}{|c|c|c|c|c|c|c|c|c|}
\hline Condition & $\begin{array}{l}H_{0} \\
(\mathrm{MJ} / \mathrm{kg})\end{array}$ & $\begin{array}{l}U_{\infty} \\
(\mathrm{km} / \mathrm{s})\end{array}$ & $\begin{array}{l}\rho_{\infty} \\
\left(\mathrm{g} / \mathrm{m}^{3}\right)\end{array}$ & $\begin{array}{l}p_{\infty} \\
(\mathrm{kPa})\end{array}$ & $\begin{array}{l}T_{\infty} \\
(\mathrm{K})\end{array}$ & $M_{\infty}$ & $\begin{array}{l}\text { Leading } \\
\text { Edge }\end{array}$ & $\begin{array}{l}\text { Shot } \\
\text { Numbers }\end{array}$ \\
\hline $\mathrm{A}[30]$ & 25.3 & 7.0 & 1.7 & 0.62 & 1300 & 9.9 & $\begin{array}{l}\text { Sharp } \\
\text { Blunt }\end{array}$ & $\begin{array}{l}x 2 s 3482-x 2 s 3484 \\
x 2 s 3504-x 2 s 3506\end{array}$ \\
\hline B [31] & 39.6 & 8.7 & 1.0 & 0.58 & 2000 & 10.3 & Sharp & $\mathrm{x} 2 \mathrm{~s} 3490-\mathrm{x} 2 \mathrm{~s} 3491$ \\
\hline $\mathrm{C}[32]$ & 53.4 & 10.1 & 2.0 & 1.07 & 1900 & 12.2 & Sharp & x2s3492- x2s3494 \\
\hline $\mathrm{D}[33]$ & 70.7 & 11.4 & 1.9 & 1.99 & 3150 & 10.3 & Sharp & $\mathrm{x} 2 \mathrm{~s} 3495-\mathrm{x} 2 \mathrm{~s} 3498$ \\
\hline $\mathrm{E}[34]$ & 50.0 & 8.3 & 15.3 & 35.04 & 5850 & 5.2 & Blunt & $\mathrm{x} 2 \mathrm{~s} 3507-\mathrm{x} 2 \mathrm{~s} 3510$ \\
\hline
\end{tabular}

The nominal test section flow properties for each condition used are shown in Table 3 The flow conditions were calculated from facility fill-pressures and measured shock speeds using PITOT, a University of Queensland in-house facility simulation code[29]. This set of flow conditions allowed the robustness and response of DHTGs to be evaluated across a range of flow enthalpies and surface heat fluxes.

\section{B. Model and Instrumentation}

The test model used was a 1/33 scale model of a simplified centreline profile of the IXV entry vehicle[35]. The profile is simplified to a blunt-nosed wedge, with a nose radius of $21.7 \mathrm{~mm}$ and the overall length of $140 \mathrm{~mm}$. In this configuration the angle of attack was set to $45^{\circ}$. The blunt nose is replaceable with a sharp leading edge, transforming the model into a $22.5^{\circ}$ wedge. In this configuration the top of the model was set to $0^{\circ}$ angle of attack. Figure 8 shows both configurations of the model with hole numbers for heat transfer gauges and a PCB transducer sensor labelled.

The model was instrumented with a total of 10 DHTGs, 8 coaxial surface-abraded thermocouples[12], 2 thin-film heat transfer gauges, and 1 PCB 113B pressure transducer. The top side had five DHTGs (holes 1 to 5), three thermocouples (holes 6, 8, and 10), and two thin-film gauges (holes 7 and 9). The underside had five DHTGs (holes 11 to 15) and five thermocouples (holes 16 to 20). Two additional DHTGs were mounted on the stagnation point when the blunt leading edge was attached (holes 21 and 22). This arrangement of heat transfer gauges allowed comparison between the different types of gauge at equal distances from the leading edge. During the experimental campaign DHTGs which were significantly damaged or broken were replaced. The thermocouples, which were all made to the same specification, were glued permanently into the model and were not moved or replaced during the course of the test campaign. Constant current supply and signal amplification for the DHTGs was provided by the University of Queensland HTG3 amplifiers which have a bandwidth of $350 \mathrm{kHz}$. The thermocouple amplifier used had a response time of $1 \mu \mathrm{s}$. 


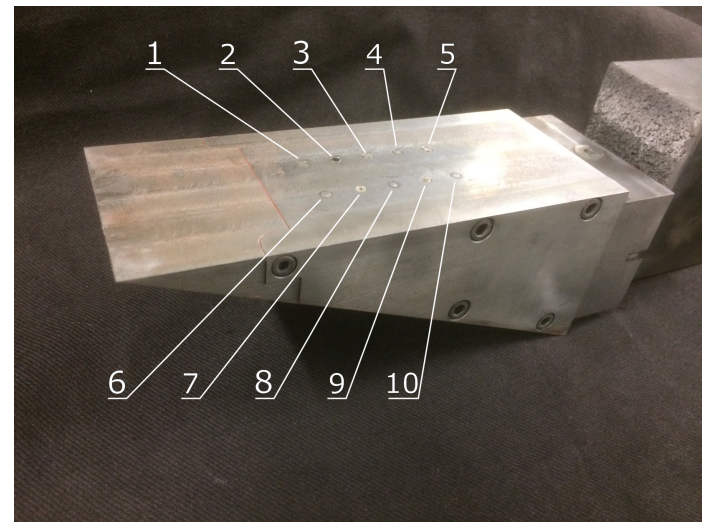

(a) Sharp leading edge.

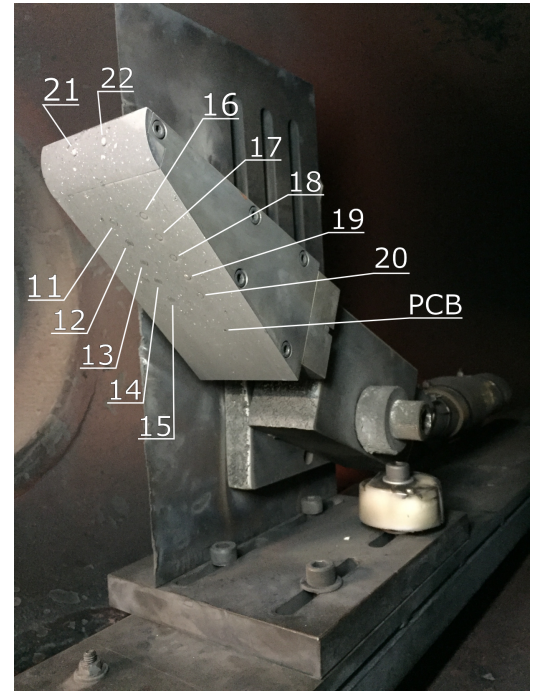

(b) Blunt leading edge.

Fig. 8 Photos of the model used for experimental testing in X2 with hole numbers labelled.

\section{Data Processing and Measurement Uncertainty}

Experimentally recorded voltages were first processed by removing the gain of the amplifiers. For the DHTGs the de-boosted voltage signal was processed into temperature using Eq. (6), and subsequently into heat flux using Eq. (3). The specific heat capacity and density of the diamond used in the equation were updated at each time-step according to the measured thin-film temperature and the temperature-dependent properties presented in Fig 3 . For the thermocouples, temperature was calculated using a sensitivity of $62.5 \mu \mathrm{V} \mathrm{K}^{-1}[13]$. To calculate the heat flux, the impulse response method developed by Oldfield[36] was used, using the standard assumption of one-dimensional semi-infinite conduction into a homogenous medium. The effective value of thermal product $(\sqrt{\rho c k})$ was taken to be $8900 \mathrm{Js}^{1 / 2} \mathrm{~m}^{-2} \mathrm{~K}^{-1}[13]$. The heat flux signals from the DHTGs and thermocouples were filtered using a low-pass filter with a cut-off frequency of $100 \mathrm{kHz}$ and $500 \mathrm{kHz}$ respectively.

The uncertainty in the heat flux measured by the DHTGs was calculated to be $11.1 \%$ by combining the uncertainty associated with each element of Eq. (3) using the the Root-Sum-Square method[37]. The greatest contributing factor is the uncertainty in the specific heat capacity of diamond, estimated to be $10 \%$. The uncertainty in the heat flux measured by the thermocouples is dominated by uncertainty in the value of effective thermal product used: the real value depends on the exact location of the thermocouple junction, how the junction was made, and the time-scale of interest. Estimates of measurement uncertainty on a time-scale of milliseconds for similar gauges are at least $10 \%$ [12, 14]. On a time-scale of tens of microseconds, which is of interest for the current study, the thin layer of electrical insulation between the two metals can affect heat conduction through the gauge and decrease the effective thermal product by as much as $30 \%[9]$, leading to an over-prediction in surface heat flux measurement. 


\section{Experimental Results}

\section{A. Surface Heat Flux}

The surface heat flux measured by a DHTG and a thermocouple for one shot at each flow condition are compared in Fig. 9. The heat flux traces all show a characteristic peak upon first arrival of accelerator gas, followed by the arrival of the test gas and a period of relatively steady heat transfer which is the useful test time. The end of the test time is dictated by contamination of the test flow with driver gas, indicated by a significant rise in heat transfer. The heat fluxes measured by both gauge types agree well, with the exception of Condition A and Condition E, where the DHTG measures a significantly lower heat flux. The initial peak measured by the DHTG s also smaller due to the slower response time of the DHTG.

Heat flux measurements from all three shots at Condition E, the highest enthalpy condition, are presented in Fig. 10 Each row of plots represents a different shot, while each column represents a different axial location from the leading edge, with the first column being the stagnation point. In each plot the measured heat flux from a DHTG and a thermocouple at equal distances from the leading edge are compared. On the stagnation point the heat flux from a DHTG compared to an empirical correlation developed by Sutton and Graves for generic axisymmetric blunt bodies with gases in chemical equilibrium[38]. For the non-stagnation point measurements, the thermocouples read a higher and more oscillatory heat flux than the DHTGs, but the agreement is generally good.

On some shots in the experimental campaign, the measured heat flux from both types of heat transfer gauges have large oscillations. This is most noticeable for DHTGs at low enthalpy conditions where the signal-to-noise ratio was poor and for the thermocouples at higher enthalpy conditions where the post-shock gas temperature was sufficiently high to produce ionisation which may interfere with the temperature measurement. The heat flux signal from both types of gauge was filtered using a low-pass filter with a cut-off frequency of $200 \mathrm{kHz}$. Based on the response times shown in Table 1 and assuming a first-order system, this filter does not remove any of the useful signal content from the DHTG signal, i.e. content produced by surface heat flux oscillations. Although the quoted response time of the thermocouples is of the order of microseconds, a filter that does not attenuate high frequency components (greater than $200 \mathrm{kHz}$ ) of the signal leaves oscillations on the order of $100 \mathrm{MW} / \mathrm{m}^{2}$ in the heat flux trace which are assumed to be non-physical.

\section{B. Robustness}

Between each shot in the experimental campaign, a photo was taken of the surface of each heat transfer gauge and the electrical resistance across the thin-film in each DHTG was recorded with a multimeter. The photos of the gauges in Fig. 11 show evidence of the extreme environment to which the gauges were exposed. Craters produced by impacts from diaphragm fragments can be seen on the surface of the steel model in all photos with the exception of Fig. 11a, which was taken prior to any testing.

The survival rate for DHTGs on the flat plate side of the model was $100 \%$. Of the ten DHTGs that were mounted at 


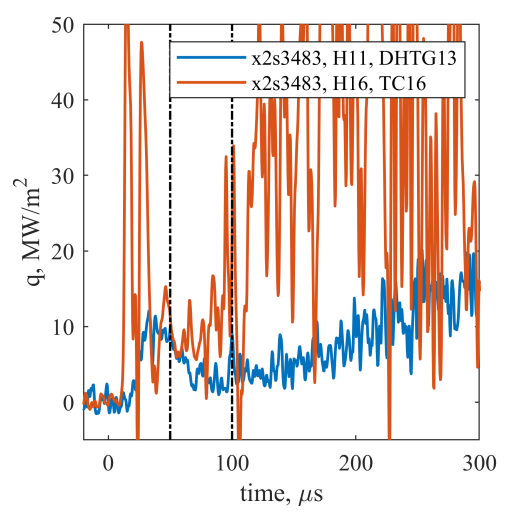

(a) Condition A, sharp leading edge

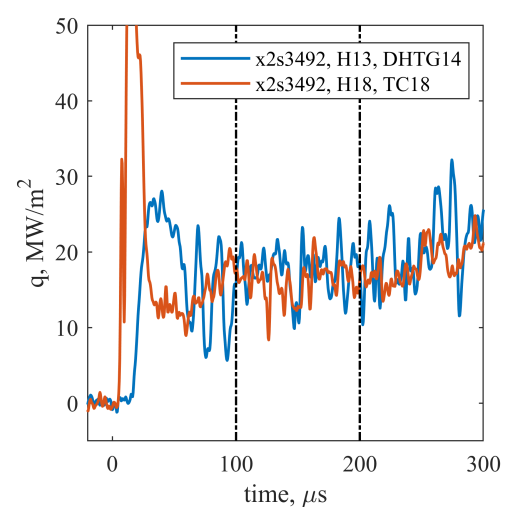

(d) Condition C

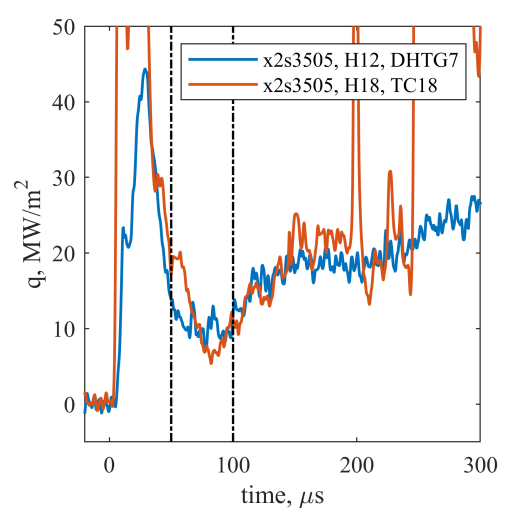

(b) Condition A, blunt leading edge

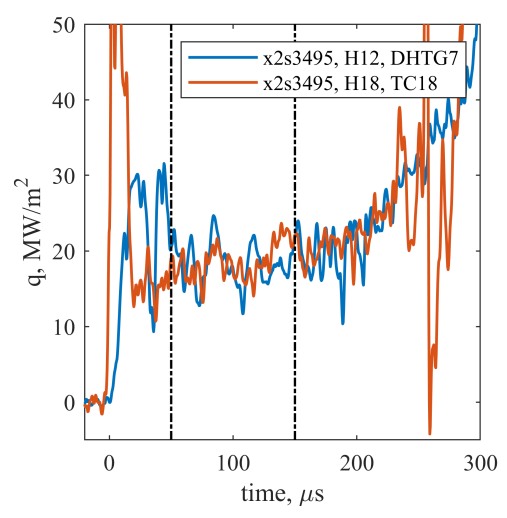

(e) Condition D

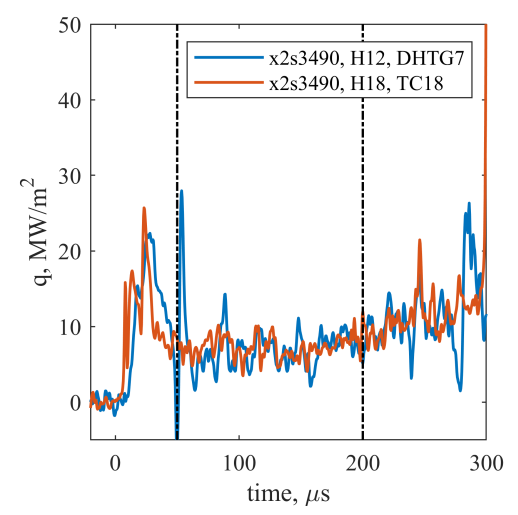

(c) Condition B

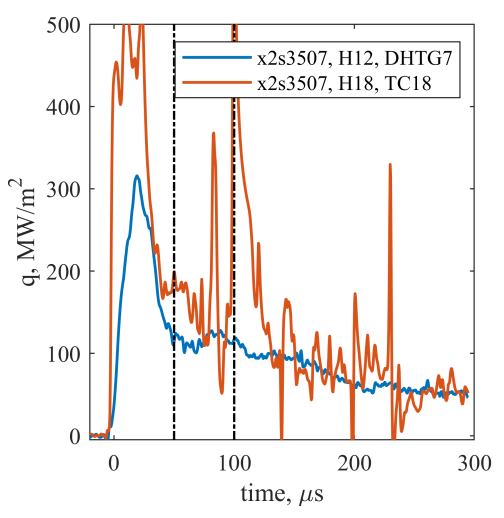

(f) Condition E

Fig. 9 Surface heat flux measured by a DHTG and a thermocouple for one shot at each condition in the experimental campaign. The test time lies between the vertical dashed lines. 


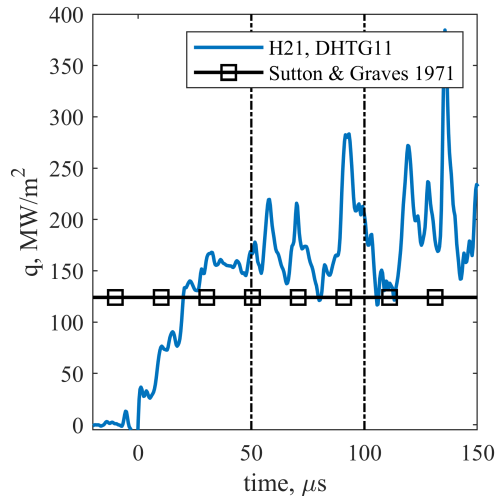

(a) $\mathrm{x} 2 \mathrm{~s} 3507, \mathrm{H} 21$ \& $\mathrm{H} 22$

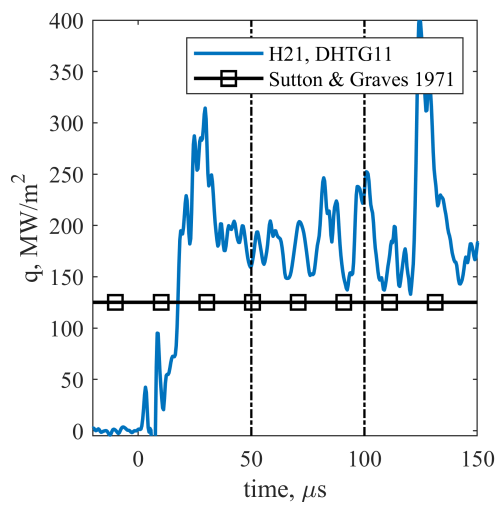

(d) $\mathrm{x} 2 \mathrm{~s} 3508, \mathrm{H} 21 \& \mathrm{H} 22$

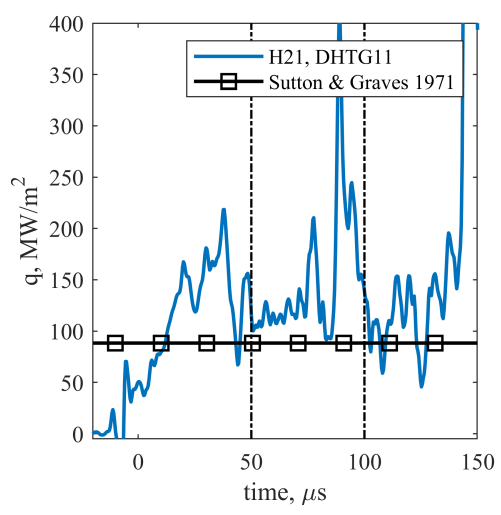

(g) $\mathrm{x} 2 \mathrm{~s} 3509, \mathrm{H} 21$ \& H22

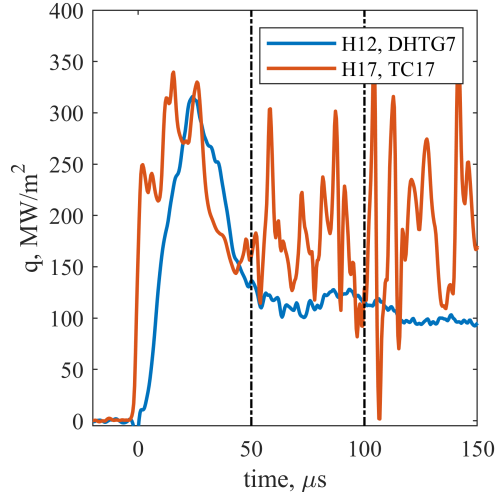

(b) $\mathrm{x} 2 \mathrm{~s} 3507, \mathrm{H} 12$ \& H17

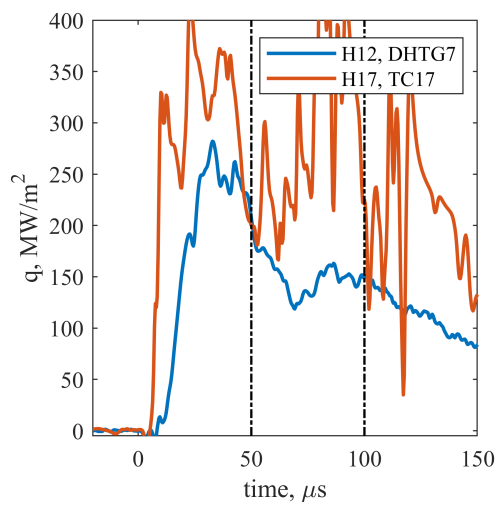

(e) $\mathrm{x} 2 \mathrm{~s} 3508, \mathrm{H} 12$ \& H17

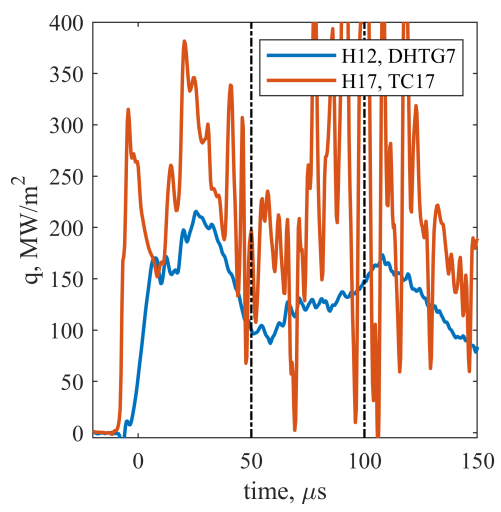

(h) $x 2 s 3509$, H12 \& H17

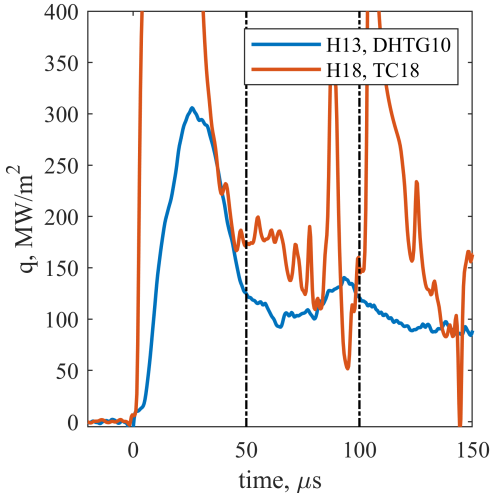

(c) $\mathrm{x} 2 \mathrm{~s} 3507, \mathrm{H} 13 \& \mathrm{H} 18$

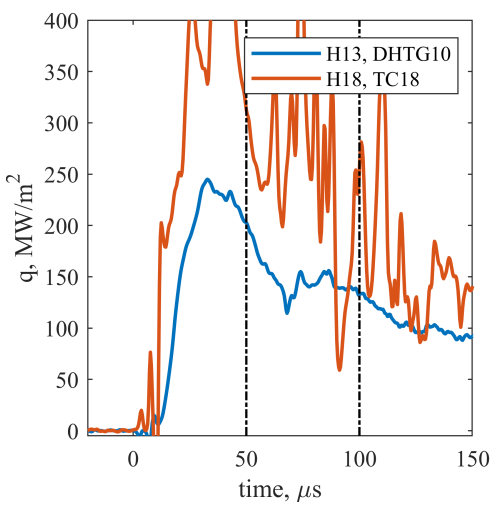

(f) $\mathrm{x} 2 \mathrm{~s} 3508, \mathrm{H} 13 \& \mathrm{H} 18$

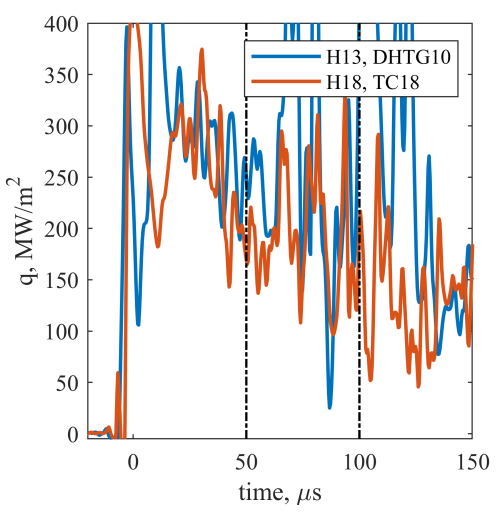

(i) $\mathrm{x} 2 \mathrm{~s} 3509, \mathrm{H} 13$ \& H18

Fig. 10 Measured heat flux from DHTGs and thermocouples for Condition E. Each plot shows gauges the same distance from the leading edge. The useful test time lies between the vertical dashed lines. 


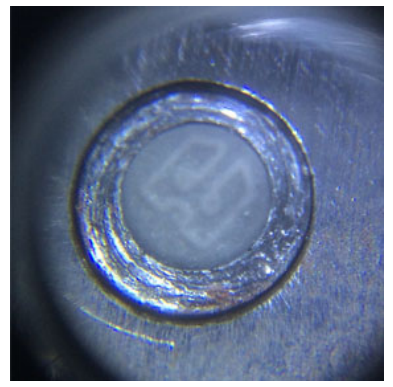

(a) DHTG15, 0 shots, working

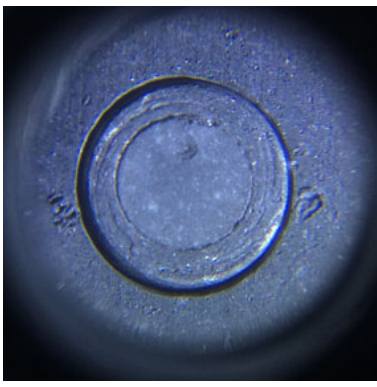

(b) DHTG15, 1 shot, broken

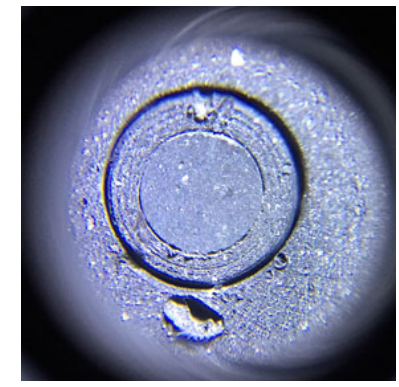

(c) DHTG7, 25 shots, working

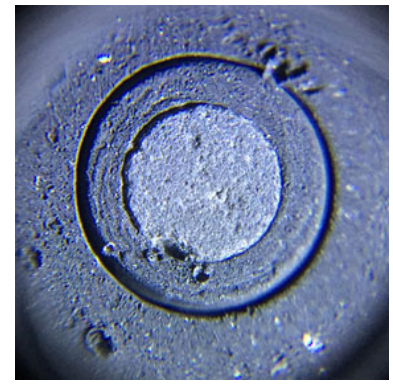

(d) DHTG11, 9 shots, working, change in electrical resistance

Fig. 11 Photos of the surface of DHTGs before, during, and after experimental testing.

an angle of attack, four ended the campaign without any sign of damage having been used for 17 shots on average. Four gauges were destroyed, surviving 1.75 shots on average. Two gauges showed a change in resistance across the thin-film but were still functional. A re-calibration of gauges after the campaign had ended (see Section II.C) showed that a change in room-temperature resistance of more than $1 \Omega$ indicates significant deviation from the original calibration, and that therefore the heat flux measured is unreliable. Photographs of the surface of the DHTGs suggest that a singular impact from a large diaphragm fragment can break the thin-film on the rear surface of the diamond. Many smaller impacts have the effect of surface abrasion and damage does not propagate to the rear surface and damage the thin-film. The sample size was not large enough to draw conclusions about the effect of diamond thickness on robustness. The thermocouples required abrading between shots to re-make the surface junctions, however all but one of the thermocouples used was still functional at the end of the campaign.

\section{Conclusion}

A new fast-response calorimeter heat transfer gauge has been designed, fabricated, and experimentally tested. The DHTG is shown to be a viable alternative to surface abraded coaxial thermocouples for measuring surface heat fluxes in high enthalpy pulse flow wind tunnels. Although The DHTG is more susceptible to damage from diaphragm particles than thermocouples at an angle of attack in an expansion tube environment, the robustness demonstrated is promising for planned future testing in reflected shock tunnels, which have less damaging flow conditions at the cost of total enthalpy.

The measurement uncertainty of the DHTG has been quantified and is comparable to that of coaxial thermocouples. Calibration experiments involving direct measurement of the impulse response of DHTGs are planned, the results of which will reduce the heat flux measurement uncertainty by removing the need to assume material properties and physical dimensions of the gauge. 


\section{Acknowledgements}

Thanks to Trevor Godfrey and Gregory King for their delicate and patient work assembling the DHTGs, to James Carter for machining the wedge model, and to the many operators of X2 who helped run the experimental campaign. Thanks to Nathan Stern who fabricated the coaxial thermocouples and to Byrenn Birch for his work testing the performance of the thermocouples.

This work has been funded by an EPSRC grant, award reference 1658275.

\section{References}

[1] Stalker, R. J., "Modern Developments in Hypersonic Wind Tunnels," Aeronautical Journal, Vol. 110, No. 1103, 2006, pp. 21-40.

[2] Beck, W. H., Klein, C., Henne, U., Martinez Schramm, J., Wagner, A., Hannemann, K., Gawehn, T., and Guelhan, A., "Application of temperature and pressure sensitive paints to DLR hypersonic facilities:"lessons learned"," 53rd AIAA Aerospace Sciences Meeting, 2015, p. 0023.

[3] Schramm, J. M., Edzards, F., and Hannemann, K., "Calibration of Fast-Response Temperature Sensitive Paints for Their Application in Hypersonic High Enthalpy Flows," New Results in Numerical and Experimental Fluid Mechanics XI, Springer, 2018, pp. 141-151.

[4] Le Sant, Y., Marchand, M., Millan, P., and Fontaine, J., "An overview of infrared thermography techniques used in large wind tunnels," Aerospace Science and Technology, Vol. 6, No. 5, 2002, pp. 355-366.

[5] Neely, A., and Morgan, R., "Measurement of heating rates for Earth entry at $13 \mathrm{~km} / \mathrm{s}$, , 25th Plasmadynamics and Lasers Conference, Fluid Dynamics and Co-located Conferences, American Institute of Aeronautics and Astronautics, 1994. URL http://dx.doi.org/10.2514/6.1994-2606 11; M1: 0; doi:10.2514/6.1994-2606.

[6] Flaherty, W., and Austin, J., "Comparative surface heat transfer measurements in hypervelocity flow," Journal of Thermophysics and Heat Transfer, Vol. 25, No. 1, 2011, pp. 180-183.

[7] Buttsworth, D. R., Stevens, R., and Stone, C. R., "Eroding ribbon thermocouples: impulse response and transient heat flux analysis," Measurement Science and Technology, Vol. 16, No. 7, 2005, p. 1487.

[8] Mohammed, H., Salleh, H., and Yusoff, M. Z., "Design and fabrication of coaxial surface junction thermocouples for transient heat transfer measurements," International Communications in Heat and Mass Transfer, Vol. 35, No. 7, 2008, pp. 853-859.

[9] Marineau, E., and Hornung, H., "Modeling and calibration of fast-response coaxial heat flux gages," 47th AIAA Aerospace Sciences Meeting including The New Horizons Forum and Aerospace Exposition, 2009, p. 737.

[10] Sanderson, S. R., and Sturtevant, B., "Transient heat flux measurement using a surface junction thermocouple," Review of Scientific Instruments, Vol. 73, No. 7, 2002, p. 2781. 
[11] Schultz, D. L., and Jones, T., "Heat-Transfer Measurements in Short-Duration Hypersonic Facilities." Tech. rep., DTIC Document, 1973.

[12] Buttsworth, D. R., "Assessment of effective thermal product of surface junction thermocouples on millisecond and microsecond time scales," Experimental Thermal and Fluid Science, Vol. 25, No. 6, 2001, pp. 409-420.

[13] Capra, B. R., "Aerothermodynamic Simulation of Subscale Models of the FIRE II and Titan Explorer Vehicles in Expansion Tubes," Ph.D. thesis, The University Of Queensland, 2006.

[14] Mohammed, H., Salleh, H., Yusoff, M., and Campo, A., "Thermal product of type-E fast response temperature sensors,” Journal of Thermal Science, Vol. 19, No. 4, 2010, pp. 364-371.

[15] Wort, C., Sweeney, C., Cooper, M., Scarsbrook, G., and Sussmann, R., “Thermal properties of bulk polycrystalline CVD diamond," Diamond and Related Materials, Vol. 3, No. 9, 1994, pp. 1158-1167.

[16] Kaye, G., Laby, T., Noyes, J., et al., Tables of Physical and Chemical Constants, 1995, New York: Longman Scientific and Technical, 2008.

[17] Follador, R., Minucci, M., Toro, P., Trava-Airoldi, V., and Ferreira, N., "Preliminary study of CVD diamond film to improve the performance of heat flux sensors for hypersonic experiments," Diamond and related materials, Vol. 14, No. 3, 2005, pp. $637-640$.

[18] Holden, M., personal communcation, 2014. Personal Communication.

[19] Clark, T., “The Development of a Diamond-Shielded Heat Transfer Gauge for Hypersonic Test Facilities,” Master's thesis, University of Queensland, 2015.

[20] Vanyai, T., “Dynamic Calibration of Heat Transfer Gauges,” Master’s thesis, University of Oxford, 2015.

[21] Graebner, J., "Measurements of specific heat and mass density in CVD diamond," Diamond and related materials, Vol. 5, No. 11, 1996, pp. 1366-1370.

[22] Coe, S., and Sussmann, R., "Optical, thermal and mechanical properties of CVD diamond," Diamond and Related Materials, Vol. 9, No. 9-10, 2000, pp. 1726-1729.

[23] Smithells, C. J., Metals reference book, Elsevier, 2013.

[24] Collins, M., Chana, K., and Povey, T., "New technique for the fabrication of miniature thin film heat flux gauges," Measurement Science and Technology, Vol. 26, No. 2, 2015, p. 025303.

[25] COMSOL AB, S., Stockholm, “COMSOL Multiphysics® v. 5.2,” , ???? URL www . comsol .com

[26] James, C., Gildfind, D., Morgan, R. G., Jacobs, P. A., and Zander, F., "Designing and simulating high enthalpy expansion tube conditions," APISAT 2013: 2013 Asia-Pacific International Symposium on Aerospace Technology, Japan Society for Aeronautical and Space Sciences, 2013, pp. 1-10. 
[27] Gildfind, D. E., Morgan, R. G., and Jacobs, P. A., "Expansion tubes in Australia," Experimental Methods of Shock Wave Research, Springer, 2016, pp. 399-431.

[28] Morgan, R., Free piston driven expansion tubes, Academic Press, 2001, Chap. 4.3, pp. 603-622.

[29] James, C. M., Gildfind, D. E., Lewis, S. W., Morgan, R. G., and Zander, F., "Implementation of a state-to-state analytical framework for the calculation of expansion tube flow properties," Shock Waves, 2017. doi:10.1007/s00193-017-0763-3, URL https://doi.org/10.1007/s00193-017-0763-3

[30] Vella, S., "Expansion Tunnel Heat Transfer Measurements of the ESA-IXV Re-entry Vehicle,” B.E. Honours thesis, The University of Queensland, 2016.

[31] Zander, F., Morgan, R., Sheikh, U., Buttsworth, D., and Teakle, P., "Hot-wall reentry testing in hypersonic impulse facilities," AIAA journal, Vol. 51, No. 2, 2013, pp. 476-484.

[32] Fahy, E., Buttsworth, D., Gollan, R., Jacobs, P., and Morgan, R. G., "Experimental and Computational Fluid Dynamics Studies of Superorbital Earth Re-entry,” 46th AIAA Thermophysics Conference, 2016, p. 3532.

[33] Sheikh, U. A., Morgan, R. G., and McIntyre, T. J., "Vacuum Ultraviolet Spectral Measurements for Superorbital Earth Entry in X2 Expansion Tube,” Aiaa Journal, Vol. 53, No. 12, 2015, pp. 3589-3602.

[34] Cullen, T., James, C., Gollan, R., and Morgan, R. G., "Development of a Total Enthalpy and Reynolds Number Matched Apollo Re-entry Condition in the X2 Expansion Tunnel,” 31st International Symposium on Shock Waves, 2017.

[35] Roncioni, P., Ranuzzi, G., Marini, M., Paris, S., Cosson, E., and Walloschek, T., "Experimental and numerical investigation of aerothermal characteristics of hypersonic intermediate experimental vehicle," Journal of Spacecraft and Rockets, Vol. 48, No. 2, 2011, pp. 291-302.

[36] Oldfield, M. L. G., “Impulse Response Processing of Transient Heat Transfer Gauge Signals,” Journal of Turbomachinery, Vol. 130, 2008.

[37] Coleman, H. W., and Steele, W. G., Experimentation, validation, and uncertainty analysis for engineers, John Wiley \& Sons, 2009.

[38] Sutton, K., and Graves Jr, R. A., "A general stagnation-point convective heating equation for arbitrary gas mixtures," Tech. Rep. TR R-376, NASA, 1971. 